\title{
Anticardiolipin antibody, recurrent thrombosis, and warfarin withdrawal
}

\author{
R A ASHERSON, ${ }^{1}$ J K H CHAN,${ }^{1}$ E N HARRIS ${ }^{2}$ A E GHARAVI, \\ AND G R V HUGHES
}

From the ${ }^{I}$ Rheumatology Unit, Department of Medicine, Royal Postgraduate Medical School, Hammersmith Hospital, Du Cane Road, London W12 OHS; and the ${ }^{2}$ Rheumatology Unit, St Thomas' Hospital, Lambeth Palace Road, London SE1 $7 E H$.

SUMMARY Antibodies to cardiolipin, closely related to the 'lupus anticoagulant', are strongly implicated in the pathogenesis of thrombosis. We record six patients, all with high titres of these antibodies ( $>$ SD) in serum, who developed recurrent vascular occlusions six to 12 weeks after warfarin withdrawal. Five of the six had deep vein thrombosis, while the sixth suffered a myocardial infarction. To minimise the risk of 'recurrent' thrombosis it is strongly suggested that such patients remain on long-term anticoagulation, pending the reduction of high antibody levels.

Key words: cardiolipin antibodies, systemic lupus erythematosus.

The 'lupus anticoagulant' and antibodies to cardiolipin ${ }^{2}$ have been associated with an increased incidence of both venous and arterial thromboses, particularly cerebral occlusions ${ }^{3}$ in patients with systemic lupus erythematosus (SLE), other autoimmune disorders, ${ }^{3 a}$ and after the administration of certain drugs. ${ }^{4}$ An increased frequency of these antiphospholipid antibodies has also been associated with pulmonary hypertension in SLE. ${ }^{5}$ A close correlation between the lupus anticoagulant and anticardiolipin antibodies has been shown, ${ }^{6}$ and the subject has recently been reviewed. ${ }^{78}$

In a retrospective study of patients with high anticardiolipin antibody we have observed six patients with recurrence of thrombosis several weeks after cessation of warfarin. Five patients had SLE. The sixth patient had some features of an autoimmune disease. Four patients were female, two were male, aged 17 to 43 years. All of them were previously maintained on warfarin for three months to three years because of deep vein thrombosis (DVT) or pulmonary thromboembolism, or both. Thrombosis recurred two to 12 weeks (in four of the patients over six weeks) after warfarin was stopped. Five had deep vein thrombosis (two confirmed by venogram), and one had a myocardial infarction (confirmed by electrocardiography and

Accepted for publication 26 April 1985.

Correspondence to Dr E N Harris, Rheumatology Unit, St Thomas' Hospital, Lambeth Palace Road, London SE1 7EH. cardiac enzyme changes). Subsequent angiographic studies of this latter patient showed normal coronary vessels. At the time when they developed recurrence of thrombosis four were on prednisone, two on azathioprine, and one on hydroxychloroquine. None of the six patients developed further thromboembolic events after reintroduction of warfarin. All had raised anticardiolipin antibodies at the time of their recurrent thromboses.

\section{Case reports}

CASE 1

A young female of 22 presented in 1973 at the age of 13 years with polyarthralgias and facial rash. She was given a short course of prednisone therapy in addition to antimalarials. At the age of 17 she experienced a recrudescence of joint pains and was diagnosed as having SLE on the basis of a positive deoxyribonucleic acid (DNA) binding (96\%), positive antinuclear factor (ANF) (1/320), a raised erythrocyte sedimentation rate (ESR) $(62 \mathrm{~mm} / 1 \mathrm{st}$ h), and proteinuria. In July 1980 she developed a DVT in the right leg and was given a short course of heparin and started on warfarin therapy. Warfarin was continued for three months; three months after cessation of therapy she developed a right femoral vein occlusion. This was again treated with heparin and warfarin therapy. She is presently maintained on long-term anticoagulant therapy and antimalarials (hydroxychloroquine $200 \mathrm{mg}$ daily). 
C A S E 2

This 42-year-old female was diagnosed as having SLE in 1980 at the age of 38 years. She had complained of polyarthralgias, lymphadenopathy, alopecia, and a skin rash. DNA binding was positive $(95 \%)$, and she had a positive antinuclear antibody (ANA) test $(1 / 160)$. There had been a history of a DVT at the age of 28 years, occurring in the postpartum period. Prednisone and azathioprine were commenced at the time of diagnosis. Soon after discontinuation of therapy a pulmonary embolus occurred, and warfarin was commenced and continued for the next three years. Superficial thrombophlebitis of the right leg extending into the deep venous system developed six weeks after the cessation of therapy, and anticoagulation was restarted.

\section{CASE 3}

This 38-year-old female was diagnosed as having SLE at the age of 18 years, though at the age of 10 she had developed an autoimmune haemolytic anaemia. Her problems had been recurrent serositis, severe flexor tendonitis of the hands, vasculitis, and cerebral lupus. Recurrent DVTs commenced at the age of 25 and 26 years, and she had been on heparin and warfarin for these episodes. Two weeks after the cessation of warfarin therapy (commenced after the second DVT) she had a further DVT. The 'lupus anticoagulant' and antibodies to cardiolipin were positive in addition to strongly positive DNA binding, raised ESRs, and positive ANA test. She continued to have intermittent flares of the SLE, and several years later had a spontaneous abortion at 18 weeks.

CASE 4

This 17-year-old male first complained of left sided pleuritic chest pain accompanied by haemoptysis in March 1984. An $x$-ray of the chest showed a minimal pleural reaction. His ESR was raised $(70 \mathrm{~mm} / 1 \mathrm{st} \mathrm{h})$, and he was treated with a course of erythromycin for suspected viral pneumonia. Two months later he had a recurrence of pleuritic pain on the right side accompanied by a small pleural effusion. A ventilation/perfusion scan showed perfusion defects that were wedge shaped and now matched by ventilation defects, consistent with a diagnosis of pulmonary emboli. The DNA binding was borderline, and the ANF was negative. There was no clinical evidence of deep venous thrombosis, but venography was not performed. Warfarin was commenced and discontinued in early June 1984. Two weeks after it was discontinued his activated partial thromboplastin time was still raised at $66 \mathrm{~s}$ (control $=43 \mathrm{~s}$ ), with a prothrombin time of $15 \mathrm{~s}$ (control $=12.5 \mathrm{~s}$ ). These results remained abnormal, and 10 weeks later he presented with a swollen left leg, which was shown at venography to be due tơ? complete occlusion of the left ileofemoral vein $\overrightarrow{\vec{F}}$ Antibodies to cardiolipin done at this stage were positive in high titre.

\section{CASE 5}

This 22-year-old Indian male first presented in March 1982 with generalised oedema and nephrotico range proteinuria. A renal biopsy showed mesangiocapillary glomerulonephritis, consistent with $\vec{P}$ diagnosis of SLE, which was also confirmed serolo $\overrightarrow{\vec{H}}$ gically (DNA binding of $98 \%$, positive ANF $1 /{ }^{\omega}$ 1560). Treatment was commenced with high dose steroids and $150 \mathrm{mg}$ of azathioprine daily. This had? been reduced to basal levels (prednisone $10 \mathrm{mg}$ daily, azathioprine $150 \mathrm{mg}$ daily) by December of 1982. At this time he presented with pleuritic chesp pain, and ventilation/perfusion scanning of the lungs $s^{\omega}$ confirmed the diagnosis of a right mid-zone pulmon-? ary embolus.

He was maintained on warfarin therapy and basa immunosuppression from December 1982 to July 1984 , during which time the nephrotic range pro teinuria persisted.

Warfarin was stopped in early July and the patient: presented three weeks later, after playing teni with a myocardial infarction. Electrocardiograp画y (ECG), echocardiography, and cardiac enzy elevations confirmed this, and he made a goods recovery.

Angiography showed normal coronary vessels and the patient was restarted on anticoagulan $\mathbb{Q}$ therapy. The patient demonstrated the 'lupus anti $\overrightarrow{\overrightarrow{0}}$ coagulant' and a high titre of anticardiolipin anti- 3 bodies in serum at the time of the coronary occlusion?

CASE 6

This 44-year-old West Indian female first develope pleuritic chest pain at the age of 35 years, followedo three years later by a deep venous thrombosis of the left leg. This was treated with anticoagulant therapyo for two months (warfarin). The following year she developed polyarthralgias, polymyalgias, Raynaud's? phenomenon, skin rash, and mouth ulcers, and a diagnosis of SLE was made on the basis of theo clinical symptomatology and confirmatory blood findings. At age 40 a right sided deep venous thrombosis occurred, and she was maintained on $N_{0}$ anticoagulants on this occasion. After two years స్ట they were discontinued because of a gastrointestinalo haemorrhage. Two months later a further right deep vein thrombosis occurred, followed by pulmonary embolisation, which subsequently became infected. $\stackrel{\oplus}{?}$

Other complications of the SLE included mem $\square$ branous nephritis and pericardial effusion. She iso being maintained on long-term steroid therapy 
(prednisone $20 \mathrm{mg}$ daily) and anticoagulants (warfarin). Estimations of anticardiolipin antibodies performed on stored serum in 1979-80 were markedly positive.

\section{Discussion}

Warfarin administration is indicated for three to six months for initial episodes of deep venous thrombosis or pulmonary embolus and long-term for recurrent venous thromboembolism, valvular heart disease with atrial fibrillation, and for patients with cardiac valve prostheses. ${ }^{9}$

It was usual in the past to tail off warfarin dosage over several weeks after the completion of therapy to reduce the risk of 'rebound' hypercoagulability and the consequent risk of thromboembolism. However, in practice this has not become routine. Although Sise ${ }^{10}$ in 1961 supported this concept, Michaels could not confirm any greater incidence of thromboembolism if oral anticoagulants were suddenly stopped or tailed off slowly. ${ }^{11}$ It has since been shown that warfarin induced clotting factors return to normal levels at most over a period of days after cessation of therapy. ${ }^{11}$

Repeat venous or arterial occlusions occurring as in the present report some two to 12 weeks after the cessation of anticoagulation therapy do not qualify as 'rebound' phenomena but rather as 'recurrent' thromboses. To account for this particular phenomenon it would be necessary first to define a hypercoagulable state existing at the time and then to investigate the patient for the existence of factors that might predispose to the state. Such a state may be induced by a transitory depression of protein $C$, and high titres of inhibitors of plasminogen activators might also predispose to recurrent thromboembolism ${ }^{12}$ as may an abnormality of protein $S^{13}$ (which serves as a cofactor for activated protein C) ${ }^{1314}$ or antithrombin III deficiency. ${ }^{15}$ It has been shown, however, in our laboratories that the latter is not operating in our patients with SLE and venous thromboses. ${ }^{16}$

Recently the presence of anticardiolipin antibodies has been shown to be associated with a greatly increased risk of venous and arterial thrombosis. ${ }^{2}$ This antibody is similar if not identical to the antiphospholipid antibody confusingly known as the 'lupus anticoagulant' - also regarded to be a risk factor for thrombosis. ${ }^{1}$

The present report suggests that anticoagulation is distinctly important in preventing recurrences of thrombosis in this group of patients and that this treatment should be used indefinitely in patients showing high titres of anticardiolipin antibodies. The quantitative estimation of the anticardiolipin antibodies appears to represent a significant advance in the assessment of the risk of recurrent venous or arterial thrombosis in these patients, and the importance of their evaluation is also supported by the recent demonstration of their association with mesenteric, ${ }^{16}$ placental, ${ }^{17}$ and other large vessel arterial occlusions. ${ }^{18}$

We would like to thank Miss Selina Lydon for secretarial assistance.

\section{References}

1 Boey M L, Colaco C B, Gharavi A E, Elkon K B, Loizou S, Hughes G R V. Thrombosis in systemic lupus erythematosus: striking association with the presence of circulating lupus anticoagulant. $\mathrm{Br}$ Med J 1983; 287: 1021-3.

2 Harris E N, Gharavi A E, Boey M L, et al. Anticardiolipin antibodies: detection by radioimmunoassay and association with thrombosis in systemic lupus erythematosus. Lancet 1983; ii: 1211-4.

3 Harris E N, Gharavi A E, Asherson R A, Boey M L, Hughes G R V. Cerebral infarction in systemic lupus: association with anticardiolipin antibodies. Clin Exp Rheumatol 1984; 2: 47-51.

3a Asherson R A, Chan J K H, Harris E N, Gharavi A E, Hughes G R V. Clinical and laboratory features associated with anticardiolipin antibodies in non-SLE patients [Abstract]. Arthritis Rheum 1985; 28: S77.

4 Mueh J R, Herbst K D, Rapaport S I. Thrombosis in patients with the lupus anticoagulant. Ann Intern Med 1980; 92: 156-9.

5 Asherson R A, Mackworth-Young C G. Boey M L. et al. Pulmonary hypertension in systemic lupus erythematosus. $\mathrm{Br}$ Med J 1983; 287: 1024-5.

6 Harris E N, Loizou S, Englert H, et al. Anticardiolipin antibodies and lupus anticoagulant. Lancet 1984; ii: 1099.

7 Hughes G R V. Thrombosis, abortion, cerebral disease and the lupus anticoagulant. $\mathrm{Br}$ Med $J$ 1983; 287: 1088-9.

8 Anonymous. Lupus anticoagulant [Editorial]. Lancet 1984; i: 1157-8.

9 Wessler S, Gitel S N. Warfarin from bedside to bench. N Engl J Med 1984; 311: 645-52.

10 Sise H S, Moschos C B, Gauthier J, Becker R. The risk of interrupting long-term anticoagulant treatment. A rebound hypercoagulable state following haemorrhage. Circulation 1961; 24: 1137 .

11 Michaels L. Incidence of thrombo-embolisms after stopping anticoagulant therapy. JAMA 1971; 215: 595.

12 Alexandre $P$, Larcan A, Biquel M E. Recurring thromboembolic accidents caused by family-related deficiency of the fibrinolysis system. Blut 1980; 41: 437-44.

13 Comp P C, Esmon C T. Recurrent venous thromboembolism in patients with a partial deficiency of protein S. N Engl J Med 1984; 311: 1525-8.

14 Comp P C, Esmon C T. Evidence for multiple roles of activated protein $\mathrm{C}$ in fibrinolysis. In: Mann K G, Taylor $\mathrm{F} \mathrm{B} \mathrm{Jr,} \mathrm{eds.} \mathrm{The}$ regulation of coagulation. New York: Elsevier, 1980: 583-8.

15 Boey M L, Loizou S, Colaco C B, Harkin J A, Hughes G R V. Antithrombin III in systemic lupus erythematosus. Clin Exp Rheumatol 1984; 2: 53-6.

16 Asherson R A, Morgan S H, Harris E N, Gharavi A E, Krausz $T$, Hughes G R V. Arterial occlusion causing large bowel infarction-a reflection of clotting diathesis in SLE? Clin Rheumatol (in press).

17 Derue G J, Englert H J, Harris E N, Elder M, Hawkins D, Hughes G R V. Abortion in systemic lupus: association with antiphospholipid antibodies. J Obstet Gynaecol 1985; 5: 104-6.

18 Asherson R A. Harris E N, Gharavi A E, et al. Arterial occlusions associated with antibodies to cardiolipin [Abstract]. Arthritis Rheum 1985; 28: S89. 
reading it and both they and their consultants will find it a useful reference work.

Senior Lecturer in Rheumatology, A C S KEAT Westminster Hospital

Paraproteins in Disease. By W Pruzanski and E C Keystone. Pp. 195. £30·00. Churchill Livingstone: Edinburgh. 1985.

This eighth volume of the series-Practical Methods in Clinical Immunology - aims to describe the laboratory tests presently employed for investigation of paraproteinaemias in relation to the clinical conditions with $\mathrm{M}$ components for the benefit of physicians, clinical biochemists, technologists, and students. A large part of the book sets out practical methods in detail and there is sufficient clinical background for the aim to be largely achieved. Several chapters deal with rather peripheral topics and/or are written in such a general way as to be of little practical use (e.g. the chapters on lymphocyte studies and hybridoma monoclonal antibodies); and I regretted the absence of anything dealing with anti-idiotypic reagents, preparation and use.

Consultant Immunologist,

D R BAINBRIDGE The London Hospital.

\section{Notes}

\section{IXth Panamerican Congress of Rheumatology}

The congress will be held on 17-22 November 1986 in Buenos Aires, Argentina. Abstracts in English, Portuguese or Spanish to be submitted by 2 May 1986. Further information from Dr O Hubscher, Secretary General, IX PANLAR Congress, Austria 2469-7 “ “A”, 1425-Buenos Aires, Argentina.

\section{XIth European Rheumatology Congress}

The congress will be held in Athens, Greece from 28 June to 4 July 1987. Main topics will be adult inflammatory joint diseases; autoimmune connective tissue diseases; juvenile rheumatism; degenerative joint diseases; crystal induced arthropathies; metabolic bone diseases; soft tissue rheumatism and mechanical spine disorders; miscellaneous bone disorders and malignant tumours; orthopaedic intervention; rehabilitation and physical therapy in the rheumatic diseases; and medical-social aspects. Details of the scientific programme from Professór H H Moutsopoulos,
University of Ioannina Medical School, Ioannina, Greece. General information from Horizon, 14 Nikis Street, GR-105 57 Athens, Greece.

\section{Marisa Ara European Prize in Rheumatology}

A prize of two million Italian lira will be awarded to a European woman rheumatologist on the basis of rheumatological research published during the past five years. Papers in Italian, French, English, or German will be considered. Closing date for entries is 30 April 1986. Further information from Professor Carla Caianiello, Via Posillipo 102-2, 80123 Napoli, Italy.

Correction: Anticardiolipin antibody, recurrent thrombosis and warfarin withdrawal

In the paper by Drs R A Asherson, J K Chan, E N Harris, A E Gharavi, and G R V Hughes (Ann Rheum Dis 1985; 44: $823-5$ ) the term ( $>$ SD) in the Summary should have read $(>7 \mathrm{SD})$; and reference 16 in the last sentence of the Discussion should have been deleted. 